Artikel Penelitian

\title{
Kajian Karakteristik Karboksimetil Selulosa (CMC) dari Pelepah Kelapa Sawit sebagai Upaya Diversifikasi Bahan Tambahan Pangan yang Halal
}

The Study of Carboxymethyl Cellulose (CMC) Characteristics from Palm Midrib As Halal Food Additives Diversification

Mokhamad Khoiron Ferdiansyah ${ }^{1^{*}}$, Djagal Wiseso Marseno ${ }^{2}$, Yudi Pranoto ${ }^{2}$

${ }^{1}$ Program Studi Teknologi Pangan Fakultas Teknik Universitas PGRI Semarang

${ }^{2}$ Program Studi IImu dan Teknologi Pangan Fakultas Teknologi Pertanian Universitas Gadjah Mada, Yogyakarta

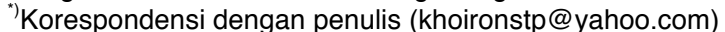

Artikel ini dikirim pada tanggal 12 Mei 2016 dan dinyatakan diterima tanggal 13 Oktober 2016. Artikel ini juga dipublikasi secara online melalui www.jatp.ift.or.id. Hak cipta dilindungi undang-undang. Dilarang diperbanyak untuk tujuan komersial.

Diproduksi oleh Indonesian Food Technologists ${ }^{\circledR}\left(\mathrm{C}_{2016}\right.$

\begin{abstract}
Abstrak
Penggunaaan bahan tambahan pangan (BTP) menjadi salah satu kebutuhan dalam industri pengolahan pangan. Bahan penstabil pangan, seperti gelatin merupakan bagian dari BTP yang rawan bersumber dari bahan haram. Oleh karena itu diperlukan alternatif bahan penstabil lain yang bisa dimanfaatkan dalam pengolahan pangan yang bersumber dari bahan halal. Karboksimetil selulosa (CMC) merupakan bahan tambahan pangan dengan kode E 466 yang mempunyai peranan sebagai penstabil pangan. CMC dapat disintesis dari pelepah kelapa sawit yang mengandung selulosa dengan kadar $89 \%$. Sebelum diaplikasikan dalam pengolahan pangan, perlu dilakukan kajian karakteristik CMC dari sumber pelepah kelapa sawit. Hasil karakterisasi CMC pelepah kelapa sawit telah memenuhi standar untuk diaplikasikan dalam pangan. Hasil karakterisasi tersebut antara lain, mempunyai nilai DS 0,75 ; kadar air $7,65 \%$; dan nilai $\mathrm{pH} 6,72$. Sedangkan hasil karakterisasi yang lain seperti nilai kemurnian $91,12 \%$ dan viskositas $11,65 \mathrm{cps}$ belum memenuhi standar FAO. Data lain menunjukkan CMC pelepah kelapa sawit mempunyai nilai WHC 6,76 (g/g); OHC 1,69 (g/g) dan tingkat kecerahan 70,46.
\end{abstract}

Kata kunci: karakteristik, karboksi metil selulosa, pelepah kelapa sawit, bahan tambahan pangan, halal

\section{Abstract}

The use of food additives be one of the necessities at the food processing industry. Food stabilizers such as gelatin was part of the food additives that were prone sourced from illicit material. Therefore it was necessary an alternative other stabilizers can be used in food processing derived from halal ingredients. Carboxymethyl cellulose $(C M C)$ was a food additive with the code E466 which has a role as a stabilizing food. CMC can be synthesized from palm midrib that contain cellulose content of $89 \%$. Before applied in food processing, necessary to study the characteristics of the CMC from palm midrib. The results of characterization palm midrib CMC has met the standards to be applied in food. The characterization results include a DS value of 0.75 ; water content of $7.65 \%$; and a $\mathrm{pH}$ value of 6.72. While the results of the other characterizations such as the value of purity of $91.12 \%$ and a viscosity of $11.65 \mathrm{cps}$ not meet FAO standards. Other data show the CMC palm midrib WHC has a value of 6.76 (g /g); $\mathrm{OHC} 1.69(\mathrm{~g} / \mathrm{g})$ and 70.46 lightness degree.

Keywords: characteristics, carboxymethyl cellulose, palm midrib, food additive, "halal"

\section{Pendahuluan}

Penggunaaan bahan tambahan pangan (BTP) menjadi salah satu kebutuhan dalam industri pengolahan pangan. Bahan penstabil merupakan bagian dari bahan tambahan pangan yang sering digunakan pada proses pengolahan produk pangan seperti pada ice cream, minuman kemasan, saos sambal, dan masih banyak lagi. Keberadaan penstabil diperlukan agar bentuk fisik produk lebih kental dan tingkat homogenitasnya lebih stabil. Bahan penstabil pangan, seperti gelatin merupakan bagian dari bahan tambahan pangan yang rawan bersumber dari bahan haram. Oleh karena itu diperlukan alternatif bahan penstabil lain yang bisa dimanfaatkan dalam pengolahan pangan yang bersumber dari bahan halal. Karboksimetil selulosa (CMC) merupakan bahan tambahan pangan dengan kode E 466 yang mempunyai peranan sebagai penstabil pangan. Karboksimetil selulosa memiliki kelebihan dibandingkan dengan penstabil pangan yang lain, yaitu dapat larut air dalam kondisi suhu panas maupun suhu dingin. Karboksimetil selulosa disintesa dari bahan nabati, sehingga status kehalalannya bisa lebih dipertanggungjawabkan.

Karboksimetil selulosa dapat disintesa dari pelepah kelapa sawit. Pelepah kelapa sawit mempunyai kandungan selulosa sebesar $89 \%$. Selulosa merupakan bahan utama sintesa karboksimetil selulosa. Agar dapat diaplikasikan lebih luas lagi, maka karboksimetil selulosa dari pelepah kelapa sawit harus dikarakterisasi terlebih dahulu agar dapat diketahui dan dibandingkan dengan kontrol produk karboksimetilselulosa yang sudah komersial di pasaran. Kajian karakterisasi karboksimetil selulosa juga harus diacu dari FAO sebagai salah satu standar pangan di tingkat dunia. Selain karakterisasi yang dilakukan dengan parameter yang ada dalam FAO, diperlukan juga karakterisasi dengan paramater tambahan seperti analisis spektra 
FTIR, WHC, OHC, dan lightness sebagai data pendukung. Kajian karakteristik karboksimetil selulosa (CMC) dari pelepah kelapa sawit ini bertujuan sebagai upaya diversifikasi bahan tambahan pangan yang halal dengan aplikasi yang luas dalam industri pengolahan pangan.

\section{Materi dan Metode \\ Materi}

Penelitian ini menggunakan pelepah kelapa sawit yang diperoleh dari perkebunan kelapa sawit di Dusun Ngrendeng, Desa Sumberoto, Kecamatan Donomulyo, Kabupaten Malang. Bahan yang digunakan untuk proses isolasi selulosa adalah $\mathrm{NaOH}$ (technical grade), aquades, $\mathrm{NaCl}$, asam asetat, $\mathrm{NaOCl}$ (klorin), dan Na-metabisulfit. Bahan yang digunakan untuk proses sintesis CMC adalah NaMCA (Merck), isopropanol (Brataco Chemical), $\mathrm{NaOH}$, dan aquades sebagai pelarut. Sedangkan bahan yang digunakan untuk karakterisasi CMC adalah $\mathrm{NaOH}$, etanol, H2SO4, serta CMC teknis komersial sebagai pembanding.

Peralatan yang digunakan untuk proses isolasi selulosa pelepah sawit antara lain erlenmeyer $1 \mathrm{~L}$, waterbath yang dilengkapi pengatur suhu, dan pengering kabinet. Proses sintesis CMC menggunakan peralatan antara lain erlenmeyer 500 $\mathrm{ml}$, waterbath yang dilengkapi dengan pengontrol suhu dan shaker (Kottermann). Untuk karakterisasi CMC menggunakan peralatan gelas (buret, erlenmeyer, gelas beaker, batang pengaduk, pipet volume, corong dan labu ukur), viskometer Brookfield (Brookfield Engineering Laboratories, Inc) yang dilengkapi dengan spindle (LV 1, kecepatan $60 \mathrm{rpm}$ ), Fourier Transform Infra Red Spectroscopy (FT-IR) (Shimadzu FTIRPrestige 21)

\section{Metode}

Tahapan penelitian meliputi isolasi selulosa dari pelepah kelapa sawit, sintesis CMC dari selulosa pelepah kelapa sawit, dan analisis CMC. Analisis kualitas CMC meliputi derajat substitusi (DS), viskositas, $\mathrm{pH}$, kemurnian, kadar air, WHC, OHC, lightness, dan gugus fungsional (FTIR).

\section{Isolasi Selulosa dari Pelepah Kelapa Sawit}

Isolasi selulosa dilakukan dengan tahap awal penepungan pelepah kelapa sawit. Penepungan pelepah kelapa sawit dimulai dengan pemotongan dan pengeringan pelepah. Setelah dikeringkan, potongan pelepah kelapa sawit kering kemudian dihancurkan dengan menggunakan mesin penggiling dan selanjutnya dilakukan pengayakan dengan ukuran 60 mesh. Tepung pelepah sawit dimasak dengan larutan $\mathrm{NaOH} 12 \%$, suhu $100^{\circ} \mathrm{C}$ selama 3 jam yang bertujuan untuk melarutkan komponen non selulosa. Padatan yang tertinggal kemudian dilakukan pencucian dengan air bersih dari sisa $\mathrm{NaOH}$, Perendaman dengan aquades yang dicampur dengan $\mathrm{NaCl}$ dan Asam asetat. Padatan yang tertinggal saat dilakukan pencucian kemudian dilakukan bleaching dengan $\mathrm{NaOCl}$ dan $\mathrm{Na}$ metabisulfit, kemudian pencucian dengan air bersih sampai ampas (selulosa) yang diperoleh tidak berbau hipoklorit. Selulosa yang diperoleh selanjutnya dikeringkan dengan menggunakan oven.

\section{Sintesis CMC dari Selulosa Pelepah Kelapa Sawit}

Tepung selulosa pelepah sawit sebanyak 5 gram, ditambahkan dengan $100 \mathrm{ml}$ isopropanol dan dialkalisasi dengan $20 \mathrm{ml}$ larutan $\mathrm{NaOH} 10 \%$ Campuran tersebut kemudian di shaker dalam waterbath pada suhu $25^{\circ} \mathrm{C}$ selama 1 jam. Setelah dilakukan alkalisasi kemudian dilakukan proses

Tabel 1. Hasil karakterisasi CMC pelepah kelapa sawit dan CMC komersial

\begin{tabular}{clccc}
\hline No & Karakteristik & CMC Pelepah Kelapa Sawit & CMC Komersial & Standar FAO \\
\hline 1 & DS & 0,75 & 0,84 & $0,2-1,5$ \\
2 & Kadar Air (\%) & 7,65 & 10,57 & $\leq 12$ \\
3 & pH & 6,72 & 8.79 & $6,0-8,5$ \\
4 & Viskositas (cps) & 11,65 & $7.574,67$ & $\geq 25$ \\
5 & Kemurnian (\%) & 91,12 & 99,63 & $\geq 99,5$ \\
6 & WHC (g/g) & 6,76 & 9,83 & - \\
7 & OHC (g/g) & 1,69 & 1,42 & - \\
8 & Lightness & 70,46 & 83,81 & - \\
\hline
\end{tabular}

Tabel 2. Hasil spektra FTIR CMC komersial dan CMC pelepah kelapa sawit

\begin{tabular}{|c|c|c|}
\hline \multicolumn{2}{|c|}{ Bilangan gelombang $\left(\mathrm{cm}^{-1}\right)$} & \multirow[b]{2}{*}{ Gugus Ikatan } \\
\hline $\begin{array}{c}\text { CMC } \\
\text { Komersial }\end{array}$ & $\begin{array}{c}\text { CMC pelepah kelapa } \\
\text { sawit }\end{array}$ & \\
\hline 3448 & $-\quad 3417$ & - $\mathrm{OH}$ stretching \\
\hline$-\quad 2924$ & - 2924 & - $\mathrm{CH}$ streching $\mathrm{CH}_{2} \& \mathrm{CH}_{3}$ group \\
\hline 1604 & -1604 & - $\quad \mathrm{C}=\mathrm{O}$ region (konstituen $\mathrm{CMC}$ ) \\
\hline 1419 & -1419 & - $\mathrm{CH}_{2}$ scissoring (konstituen $\mathrm{CMC}$ ) \\
\hline 1327 & $-\quad 1327$ & - $\quad \mathrm{OH}$ bending \\
\hline 1111 & $-\quad 1111$ & - $\quad \mathrm{C}-\mathrm{O}-\mathrm{C}$ asymmetry bridge stretching \\
\hline 1056 & -1064 & - $\mathrm{CH}-\mathrm{O}-\mathrm{CH}_{2}$ streching \\
\hline 902 & - 902 & - 1,4- $\beta$ glikosidik \\
\hline
\end{tabular}


karboksimetilasi dengan menambahkan NaMCA 4,57 gram. Proses ini dilakukan di dalam water bath yang dilengkapi dengan shaker selama 3 jam pada suhu 46,59 C. Selanjutnya dilakukan penetralan dengan asam asetat. Setelah slurry tersebut netral maka dilakukan pencucian dengan larutan alkohol 96\%. Padatan yang diperoleh dari hasil penyaringan kemudian dikeringkan dengan menggunakan oven dengan suhu $60^{\circ} \mathrm{C}$. Padatan yang kering kemudian dilakukan penepungan dengan menggunakan blender sehinga diperoleh tepung CMC.

\section{Karakterisasi CMC}

Analisis kualitas CMC meliputi derajat substitusi (DS), viskositas, $\mathrm{pH}$, kemurnian, kadar air, WHC, OHC, lightness, dan gugus fungsional. Metode yang digunakan untuk analisis antara lain Cellogen merujuk pada metode yang dilakukan oleh Wijayani et al. (2005); anasilis derajat substitusi (DS), ASTM standard D-1439-94 untuk menganalisis tingkat kemurnian, viskositas dan kadar air merujuk pada Valencia et al. (2007) dan Ambriz et al. (2008) untuk analisis WHC dan $\mathrm{OHC}$, serta Rossel et al. (2009) untuk analisis tingkat kecerahan (lightness). SII 0674-82 menjadi acuan untuk analisis $\mathrm{pH}$. Analisis struktur menggunakan FTIR menggunakan prosedur dari Lii et al. (2002).

\section{Hasil dan Pembahasan}

Berdasarkan acuan dengan menggunakan standar FAO, hasil karakterisasi CMC pelepah kelapa sawit telah memenuhi standar untuk diaplikasikan dalam pangan. Hasil karakterisasi tersebut antara lain nilai DS 0,75; kadar air 7,65\%; dan nilai $\mathrm{pH} 6,72$. Sedangkan hasil karakterisasi yang lain seperti nilai kemurnian $91,12 \%$ dan viskositas 11,65 cps belum memenuhi standar FAO. Data lain menunjukkan CMC pelepah kelapa sawit mempunyai nilai WHC 6,76 (g/g); $\mathrm{OHC} 1,69(\mathrm{~g} / \mathrm{g})$ dan lightness 70,46. Adapun detail hasil karakterisasi CMC pelepah kelapa sawit ditunjukkan pada Tabel 1.

Derajat substitusi (DS) CMC pelepah kelapa sawit maupun CMC komersial memiliki nilai yang memenuhi standar FAO. CMC pelepah kelapa sawit dan komersial memiliki nilai DS 0,75 dan 0,84. Selisih nilai DS CMC pelepah kelapa sawit dan komersial tidak terlalu tinggi. Hal ini menunjukkan tingkat kelarutan CMC dalam air yang hampir sama. DS merupakan salah satu parameter utama keberhasilan proses sintesis CMC dari bahan baku awal selulosa. Semakin tinggi nilai DS maka polaritas CMC juga meningkat. Namun, dalam aplikasinya pada pengolahan pangan, DS CMC dibatasi dalam range 0,2-1,5. Kadar air CMC pelepah kelapa sawit maupun komersial memenuhi standar FAO, yaitu kurang dari 12\%. Kadar air berpengaruh terhadap sifat alir dan daya simpan CMC. Semakin tinggi kadar air suatu bahan maka umur simpannya menjadi tidak terlalu panjang. Hal ini disebabkan adanya kerusakan yang ditimbulkan oleh faktor fisik, kimiawi, maupun mikrobiologis. Parameter $\mathrm{pH}$ dari CMC komersial mempunyai nilai yang tidak memenuhi standar. Hal ini disebabkan bahan baku awal pembuatan CMC komersial masih belum diketahui secara jelas sumbernya. Menurut Adinugraha (2004), selama ini pembuatan CMC komersial umumnya berasal dari pulp selulosa kayu atau cotton linter saja. Tingginya nilai $\mathrm{pH}$ CMC komersial dapat disebabkan oleh proses netralisasi yang belum sempurna. Ditinjau dari viskositasnya, CMC pelepah kelapa sawit termasuk pada golongan CMC dengan viskositas rendah dibandingkan dengan viskositas CMC batang semu pisang 4033,33 cps (Adinugraha et al., 2005) nanas 81,67 cps (Susana, 2009), dan pod husk cacao 206,10 cps (Hutomo et al., 2012). Akan tetapi, pada penelitian CMC pelepah kelapa sawit mempunyai viskositas yang lebih tinggi jika dibandingkan dengan CMC enceng gondok (Wijayani et al., 2005) yang mempunyai viskositas sekitar 7-9 cps. Menurut Imeson (2010), viskositas CMC dipengaruhi oleh panjang rantai atau derajat polimerisasi (DP) selulosa. Semakin tinggi nilai derajat polimerisasi (DP) selulosa, maka viskositas CMC akan meningkat. Nilai viskositas CMC pelepah kelapa sawit yang tidak terlalu tinggi dimungkinkan disebabkan oleh derajat polimerisasi (DP) selulosa yang rendah. Hutomo (2012) menyebutkan bahwa kemurnian CMC yang masih rendah disebabkan teknik pemurnian yang masih sederhana, sehingga diperlukan teknik pemurnian CMC yang lebih baik untuk mendapatkan kemurnian yang lebih tinggi. WHC (Water Holding Capacity) CMC memiliki nilai yang sebanding dengan nilai DS dan berbanding terbalik dengan nilai OHC (Oil Holding Capacity). Hal ini dikarenakan semakin tinggi nilai DS, maka polaritas CMC juga meningkat sehingga kemampuan $\mathrm{CMC}$ dalam mengikat air menjadi lebih baik. Oleh sebab itulah, nilai $\mathrm{OHC}$ juga menurun. Tingkat kecerahan (lightness) CMC pelepah kelapa sawit lebih rendah dibandingkan dengan $\mathrm{CMC}$ komersial. Hal ini dimungkinkan terjadi karena masih ada sisa lignin pada bahan baku selulosa yang bereaksi dengan $\mathrm{NaOH}$ pada proses sintesis CMC. Tingkat kecerahan berpengaruh pada aplikasi CMC, dimana semakin cerah penampakan CMC maka daya terima konsumen cenderung lebih tinggi.

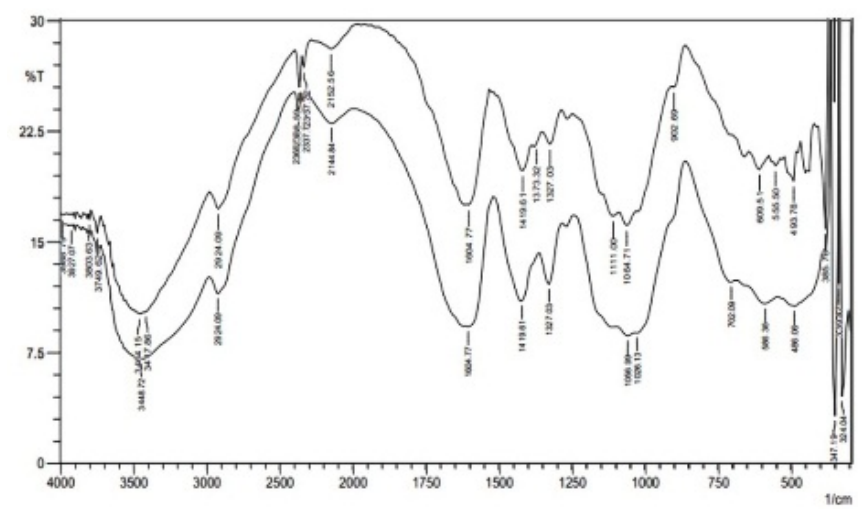

Gambar 1. Spektra FTIR CMC Pelepah Sawit (A) dan CMC Komersial (B)

Gambar 1 menunjukkan hasil analisis spektra FTIR kedua jenis sampel memiliki pola yang sama. Secara umum ciri khas spektra CMC yaitu pada puncak di bilangan gelombang $1604 \mathrm{~cm}^{-1}$ yang mencirikan 
gugus karbonil $(-\mathrm{C}=\mathrm{O})$ dan bilangan gelombang 1419 $\mathrm{cm}^{-1}$ yang menunjukkan adanya ikatan $-\mathrm{CH}_{2}$ dari konstituen karboksimetil. Bilangan gelombang $3417 \mathrm{~cm}-$ ${ }^{1}$ menunjukkan -OH stretching dan bilangan gelombang $2924 \mathrm{~cm}^{-1}$ merupakan puncak ikatan $-\mathrm{CH}$ atau $-\mathrm{CH}_{2}$ atau $-\mathrm{CH}_{3}$ dari AGU. Bilangan gelombang $1327 \mathrm{~cm}^{-1}$ merupakan puncak ikatan gugus $-\mathrm{OH}$ bending vibration, sedangkan bilangan gelombang $1064 \mathrm{~cm}^{-1}$ menunjukkan $\mathrm{CH}-\mathrm{O}-\mathrm{CH}_{2}$ streching. Bilangan gelombang $902 \mathrm{~cm}^{-1}$ menunjukkan adanya ikatan 1,4- $\beta$ glikosidik.

Hasil analisis spektra FTIR ditunjukkan pada Tabel 2. Dari tabel tersebut terlihat bahwa kedua jenis sampel memiliki pola yang sama. Secara umum ciri khas spektra CMC yaitu pada puncak di bilangan gelombang $1604 \mathrm{~cm}^{-1}$ yang mencirikan gugus karbonil $(-\mathrm{C}=\mathrm{O})$ dan bilangan gelombang $1419 \mathrm{~cm}^{-1}$ yang menunjukkan adanya ikatan $-\mathrm{CH}_{2}$ dari konstituen karboksimetil. Bilangan gelombang $3417 \mathrm{~cm}^{-1}$ menunjukkan $-\mathrm{OH}$ stretching dan bilangan gelombang $2924 \mathrm{~cm}^{-1}$ merupakan puncak ikatan $-\mathrm{CH}$ atau $-\mathrm{CH}_{2}$ atau $-\mathrm{CH}_{3}$ dari AGU. Bilangan gelombang $1327 \mathrm{~cm}^{-1}$ merupakan puncak ikatan gugus $-\mathrm{OH}$ bending vibration, sedangkan bilangan gelombang $1064 \mathrm{~cm}^{-1}$ menunjukkan $\mathrm{CH}-\mathrm{O}-\mathrm{CH}_{2}$ streching. Bilangan gelombang $902 \mathrm{~cm}^{-1}$ menunjukkan adanya ikatan 1,4- $\beta$ glikosidik.

\section{Kesimpulan}

Hasil karakterisasi CMC pelepah kelapa sawit telah memenuhi standar untuk diaplikasikan dalam pangan. Hasil karakterisasi tersebut antara lain nilai DS 0,75; kadar air 7,65\%; dan nilai pH 6,72. Sedangkan hasil karakterisasi yang lain seperti nilai kemurnian $91,12 \%$ dan viskositas 11,65 cps belum memenuhi standar FAO. Data lain menunjukkan CMC pelepah kelapa sawit mempunyai nilai WHC 6,76 (g/g); OHC $1,69(\mathrm{~g} / \mathrm{g})$ dan lightness 70,46.

\section{Daftar Pustaka}

Ambriz, S.L.R., Hernandes, J.J.L., Acevedo, E.A., Tovar, J., dan Perez, L.A.B, (2008), Characterization of a fibre-rich powder prepared by liquefaction of unripe banana flour. Journal of Food Chemistry 107, pp. 1515-1521

Anonim, (1994), Standard Test Methods for Sodium Carboxymethylcellulose. Philadelphia: ASTM Committee on Standards pp. 291-298. (ASTM : D1439-94).

Hutomo, G. S., (2012), Sintesis dan Karakterisasi Turunan Selulosa Dari Pod Husk Kakao (Theobroma cacao L.).

Disertasi. Program Pasca Sarjana UGM. Yogyakarta.

Imeson, A., (2010), Food Stabilisers, Thickeners and Gelling Agents. Willey Blackwell. United Kingdom

Lii, C., Tomasik, P., Zaleska, H., Liauw, H. dan Lai, V.M.F., (2002), Carboxymethylcellulose - Gelatin Complexes. Carbohydrate Polymers. 50, pp. 1926

Rossel, C.M., Santos, E., dan Collar, C., (2009), Physico-chemical Properties of Commercial Fibers from Different Sources : A Comparative Approach. Journal of Food Research International, 42, pp. 176-184

Valencia. N.V., Perez, E.G., Acevedo, E.A., Tovar, J., Ruales, J., dan Perez, L.A.B., (2007), Fibre Concentrate from Mango Fruit : Characterization, Associated Antioxidant Capacity and Application as a Bakery Product Ingredient. Journal of $L W T$, 40, pp. $722-729$

Wijayani, A., Ummah, K., dan Tjahjani, S., (2005), Karakterisasi Karboksimetil Selulosa (CMC) dari Enceng Gondok (Eichornia crassipes (Mart) Solms). Indo. J. Chem., 2005, 5 (3), pp. $228-231$ 